\title{
Evaluation of microhaemagglutination assay to determine treponemal antibodies in CSF
}

\author{
A. BIRRY AND S. KASATIYA \\ Irom the Laboratory Services, Quebec Department of Social Affairs, Ste-Anne-de-Bellevue, Canada
}

SINMAR) The microhaemagglutination assay for Treponema pallidum antibodies (MHA:TP$(\mathrm{SI})$, the Venereal Disease Research Laboratory (VDRL-CSF), and the fluorescent treponemal antibody (FTA-CSF) tests were used to detect treponemal antibodies in 3157 samples of ierebrospinal fluid from patients with syphilis, with neurological, metabolic, or immunological disorders, and with undetermined diagnoses. An agreement of $99 \cdot 5 \%$ between the results of the MHA:TP-CSF and FTA-CSF tests was obtained for all the CSF samples whereas that of only $95 \cdot 5 \%$ was obtained for samples from the known cases of syphilis. The MHA:TP-CSF. test is simple, economical, rapid, and specific but not as sensitive as the FTA-CSF test.

\section{Introduction}

The Treponema pallidum microhaemagglutination assay (TPHA), a relatively simple, highly specific, and sensitive test, was developed to determine the presence of syphilitic antibodies in serum (Rathlev, 1967). Later, many laboratories throughout the world started evaluating this test using a commercial antigen (manufactured by Fujizoki Pharmaceutical Company, Tokyo, Japan). Various authors compared the results of this test with those of the fluorescent treponemal antibody absorption (FTAABS) test, which until now was considered to be the confirmatory test, and found an agreement from $85 \%$ to $100 \%$ for antibodies present in the serum of syphilitic and nonsyphilitic patients (Cox et al., 1971; Garner et al., 1972; Kopecky et al., 1977; Luger and Spendlingwimmer, 1973; O'Neill et al., 1973; Sequeira and Eldridge, 1973). Studies indicate that the TPHA test is less sensitive than the FTA-ABS test in detecting cases of primary syphilis (Tomizawa, 1969; Sequeira and Eldridge, 1973; Lesinski et al., 1974). False positivity to the TPHA test in sera of healthy individuals is very rare (Coffey et al., 1972; Garner et al., 1973; O'Neill et al., 1973; Young et al., 1974), but it may frequently be observed in patients with autoimmune diseases (Lesinski et al., 1974).

While much information is available on the evaluation of the TPHA test in serum, little is

Address for reprints: Dr S. Kasatiya, Ontario Public Health Laboratory, PO Box 6301, 346 Moodie Drive, Ottawa, Ontario K2A 1S8, Canada

Received for publication 3 October 1978 described about its application in cerebrospinal fluids (CSF). Jaffe et al. (1978) found no reactivity for the TPHA test in CSF from 15 patients with latent syphilis, whereas Monsiorska-Borowska (1977) found it to be the most sensitive of the Venereal Disease Research Laboratory (VDRL), Treponema pallidum immobilisation (TPI), and FTA-ABS tests carried out on 110 samples of spinal fluid and 49 sera from patients with suspected or diagnosed late syphilis.

The present study was undertaken to evaluate the reactivity of the microhaemagglutination test in cerebrospinal fluid (MHA:TP-CSF) from nonsyphilitic and syphilitic patients at different stages and to compare it with that of the VDRL-CSF and FTA-CSF tests.

\section{Material and methods}

During the period of two years, from July 1976 to July 1978, cerebrospinal fluid specimens from 3157 patients were examined in the central laboratory for routine syphilis serology. Of these patients, 356 were known cases of syphilis confirmed by clinical examination, case history, and serology. The remaining 2801 specimens came from patients with undetermined diagnoses and from patients with neurological, metabolic, or immunological disorders. Most of the specimens were collected from the local hospitals and brought to the laboratory within 24 hours of collection. The specimens were kept at $-20^{\circ} \mathrm{C}$ until tested. No information was sought regarding the reactivity of the VDRL, FTA-ABS, and MHA:TP tests in the sera of these cases. 
Standard techniques were used for the VDRL-CSF (CDC, 1969) and MHA:TP-CSF (CDC, 1973) tests, whereas the FTA-CSF test was carried out according to the miethods described by Duncan et al. (1972) and Leclerc et al. (1978). During this period all the samples were examined simultaneously by the three tests. The MHA:TP-CSF test was carried out on uninactivated CSF using antigens and serum controls (supplied by Fujizoki Pharmaceutical Company, Tokyo, Japan).

The test was performed and interpreted according to the directions of the manufacturer as recommended for serum; the initial dilution of $1 / 20$ of the CSF sample was brought to a final dilution of $1 / 80$ after addition of the cells. The FTA-CSF reagents ( $T$. pallidum antigen, conjugate, and sorbent) were supplied by Beckman Company, Fullerton, California, USA. The FTA-CSF test was carried out routinely on undiluted, unabsorbed CSF. All the CSF samples giving a reactive result in the routine test were retested after dilution to $1 / 5$ in sorbent (supplied by the manufacturer) before being reported as giving a reactive result. Monospecific IgG conjugate was used in a dilution of $1 / 2300$ with unabsorbed CSF and of 1/600 with absorbed CSF to get the same intensity of fluorescence with strongly reactive, weakly reactive, and non-reactive CSF controls selected in the laboratory. A Leitz Orthoplan microscope equipped with an incident light system was used according to the method described by Kasatiya and Birry (1972).

\section{Results}

\section{REACTIVITY IN CSF SAMPLES}

Known and unknown diseases

Of the 3157 specimens of CSF from patients with (a) neurological, metabolic, or immunological disorders; (b) different stages of syphilis; and (c) undetermined diagnoses, $3 \cdot 1 \%, 6 \cdot 4 \%$, and $6 \cdot 9 \%$ gave reactive results to the VDRL-CSF, MHA:TP-CSF, and FTACSF tests respectively (Table 1). All of the 217 CSF samples giving a reactive result to the FTA-CSF test came from known cases of syphilis. An agreement of 96.3\% was obtained between the VDRL-CSF and MHA:TP-CSF or FTA-CSF tests whereas that of 99.5\% was found between the MHA:TP-CSF and FTA-CSF tests. False-positive results were not obtained in the VDRL-CSF, MHA:TP-CSF, or FTA-CSF tests. All of the 16 CSF samples giving a reactive result only in the FTA-CSF test came from known cases of syphilis.

\section{Syphilis}

The reactivity of the VDRL-CSF, MHA:TP-CSF, and FTA-CSF tests in CSF samples from 356 known cases of syphilis are given in Table 2 . The VDRL test gave a reactive result in only $27.5 \%$ of cases whereas in the MHA:TP-CSF and FTA-CSF tests $56.5 \%$ and $60.9 \%$ of samples respectively gave reactive results. CSF samples from 16 patients gave reactive results in only the FTA-CSF test. A poor agreement of $66.6 \%$ was obtained in this group between the VDRL-CSF and MHA:TP-CSF or FTA-CSF tests. CSF samples from $139(39 \%)$ patients with syphilis did not show any reactivity in any of the three tests.

\section{Distribution according to sex}

Percentage reactivity for the three tests in CSF samples from the 275 men and 81 women with syphilis was almost identical. Of the total $356 \mathrm{CSF}$ samples, $29.4 \%$ and $21 \%$ in the VDRL-CSF test, $57.4 \%$ and $53 \%$ in the MHA:TP-CSF test, and $60.7 \%$ and $61.7 \%$ in the FTA-CSF tests gave reactive results respectively in men and women.

\section{Primary syphilis}

All the CSF samples from 32 known cases of primary

Table 1 Results of the VDRL-CSF, MHA:TP-CSF, and FTA-CSF tests performed on CSF samples from 3157 patients

\begin{tabular}{|c|c|c|c|c|c|c|c|c|c|c|c|}
\hline & \multirow{2}{*}{\multicolumn{3}{|c|}{ Test results }} & \multirow{2}{*}{\multicolumn{2}{|c|}{$\begin{array}{l}\text { Total no. } \\
\text { of samples }\end{array}$}} & \multicolumn{6}{|c|}{ Agreement between tests } \\
\hline & & & & & & \multicolumn{2}{|c|}{$V D R L: M H A$} & \multicolumn{2}{|c|}{$V D R L: F T A$} & \multicolumn{2}{|c|}{$M H A: F T A$} \\
\hline & $V D R L$ & $M H A$ & $F T A$ & No. & $\%$ & No. & $\%$ & No. & $\%$ & No. & $\%$ \\
\hline & $\begin{array}{l}+ \\
+ \\
+ \\
- \\
- \\
+ \\
-\end{array}$ & $\begin{array}{l}+ \\
+ \\
+ \\
+ \\
+ \\
+\end{array}$ & $\begin{array}{l}+ \\
\pm \\
+ \\
+ \\
\pm \\
\pm \\
+\end{array}$ & $\begin{array}{r}98 \\
0 \\
0 \\
103 \\
16 \\
0 \\
0 \\
2940\end{array}$ & $\begin{array}{l}3 \cdot 1 \\
0 \\
0 \\
3 \cdot 3 \\
0 \cdot 5 \\
0 \\
0 \\
93 \cdot 1\end{array}$ & 3054 & $96 \cdot 7$ & 3038 & $96 \cdot 3$ & 3141 & $99 \cdot 5$ \\
\hline $\begin{array}{l}\text { Total no. } \\
\text { reactive (\%) }\end{array}$ & $98(3 \cdot 1)$ & $201(6$ & $217(6$ & & & & & & & & \\
\hline
\end{tabular}

* Includes two patients with borderline results

+ Positive - negative 
Table 2 Results of the VDRL-CSF, MHA:TP-CSF, and FTA-CSF tests performed on 356 CSF samples from known cases of syphilis

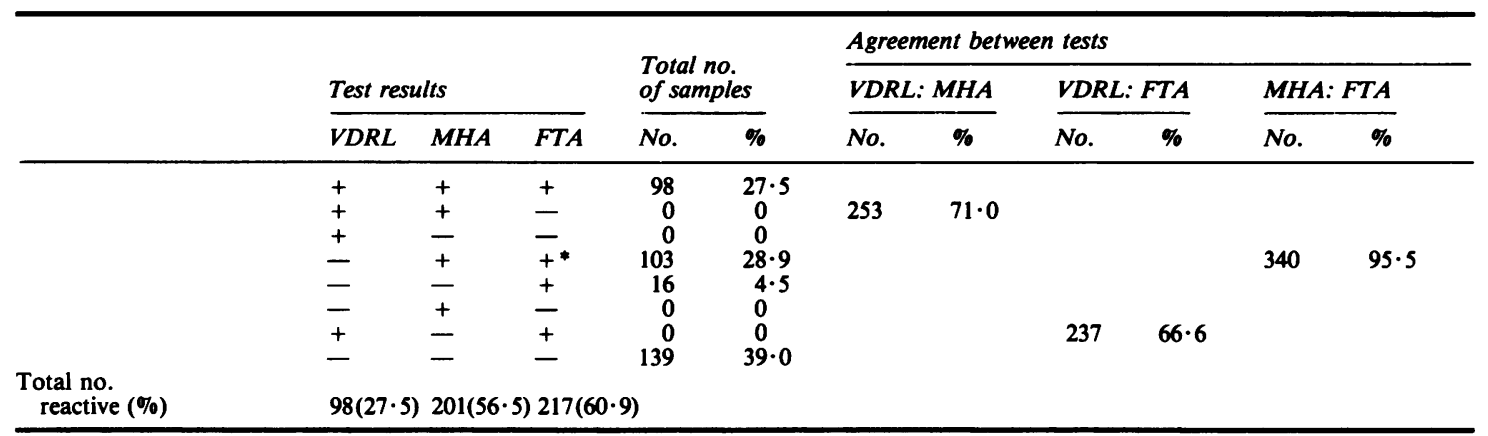

*Includes two patients with borderline results

+ Positive - negative

syphilis gave negative results to the VDRL-CSF, MHA:TP-CSF, and FTA-CSF tests.

\section{Secondary syphilis}

As many as $50.6 \%$ and $64.5 \%$ of the CSF samples gave reactive results in the MHA:TP-CSF and FTACSF tests respectively, even in cases of secondary syphilis. The VDRL-CSF test gave reactive results in only $20.2 \%$ of cases. An agreement between the VDRL-CSF and MHA:TP-CSF or FTA-CSF tests was obtained in $55.7 \%$ of cases. A good agreement was found between the MHA:TP-CSF and FTA-CSF tests in this early stage of syphilis. CSF samples from 11 cases of secondary syphilis gave reactive results only in the FTA-CSF test (Table 3).

\section{Tertiary syphilis}

All cases of asymptomatic and symptomatic neurosyphilis and cardiovascular syphilis were grouped in this category. It is in this category that most of the CSF samples gave reactive results. Of the
$121 \mathrm{CSF}$ samples $91 \cdot 7 \%$ gave reactive results in the FTA-CSF test while $88 \cdot 4 \%$ and $57 \cdot 9 \%$ gave reactive results in the MHA:TP-CSF and VDRL-CSF tests respectively (Table 4). Slightly better agreement was obtained between the VDRL-CSF and MHA:TPCSF or FTA-CSF tests and between the MHA:TPCSF and FTA-CSF tests than in cases of secondary syphilis. Of the four patients with reactive results in only the FTA-CSF test, one patient had meningovascular neurosyphilis and three asymptomatic neurosyphilis. The VDRL-CSF test was $2 \frac{1}{2}$ times more reactive in tertiary than in secondary syphilis.

\section{Latent syphilis}

The reactivity for the VDRL-CSF test dropped markedly to $9.5 \%$ in this particular group. The diminution in percentage reactivity was also observed in the MHA:TP-CSF and FTA-CSF tests (Table 5); $53.4 \%$ of the CSF samples gave no reactive results in any of these tests. Although agreement between the

Table 3 Results of the VDRL-CSF, MHA:TP-CSF, and FTA-CSF tests performed on CSF samples from 79 cases of known secondary syphilis

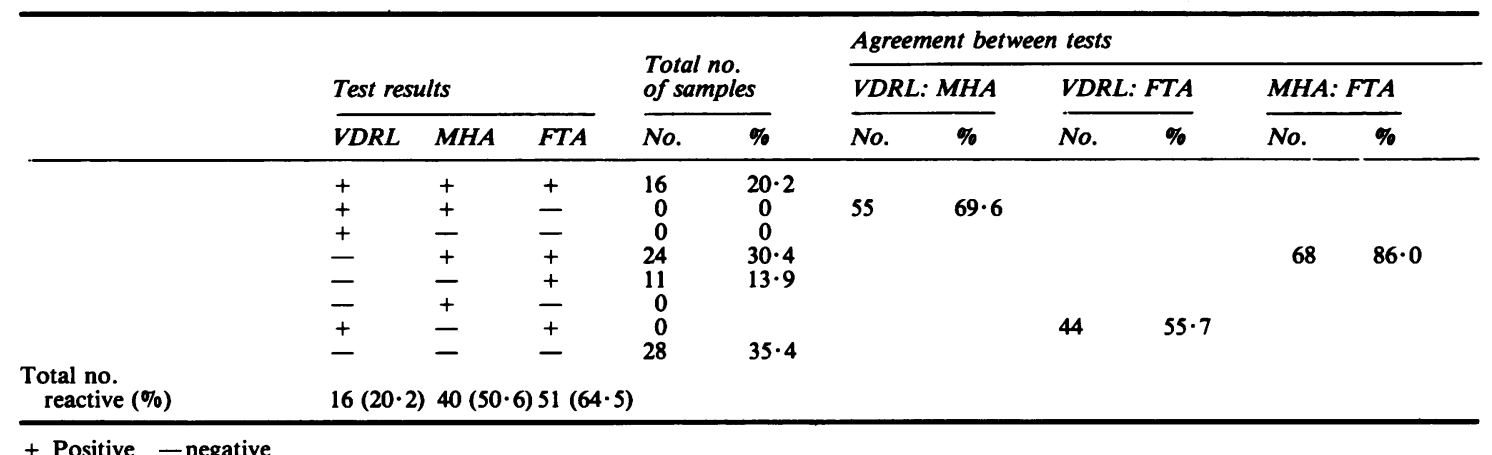

+ Positive - negative 
Table 4 Results of the VDRL-CSF, MHA:TP-CSF, and FTA-CSF tests performed on CSF samples from 12I known cases of tertiary syphilis

\begin{tabular}{|c|c|c|c|c|c|c|c|c|c|c|c|}
\hline & \multirow{2}{*}{\multicolumn{3}{|c|}{ Test results }} & \multirow{2}{*}{\multicolumn{2}{|c|}{$\begin{array}{l}\text { Total no. } \\
\text { of samples }\end{array}$}} & \multicolumn{6}{|c|}{ Agreement between tests } \\
\hline & & & & & & \multicolumn{2}{|c|}{ VDRL:MHA } & \multicolumn{2}{|c|}{$V D R L: F T A$} & \multicolumn{2}{|c|}{$M H A: F T A$} \\
\hline & $V D R L$ & $M H A$ & $\overline{F T A}$ & No. & $\%$ & No. & $\%$ & No. & $\%$ & No. & $\%$ \\
\hline \multirow[b]{2}{*}{$\begin{array}{l}\text { Total no. } \\
\text { reactive }(\%)\end{array}$} & $\begin{array}{l}+ \\
+ \\
+ \\
- \\
- \\
+ \\
+\end{array}$ & $\begin{array}{l}+ \\
+ \\
\overline{+} \\
\overline{-}^{*} \\
+ \\
-\end{array}$ & $\begin{array}{l}+ \\
- \\
+ \\
+ \\
+ \\
+ \\
+\end{array}$ & $\begin{array}{c}70 \\
0 \\
0 \\
37 \\
4 † \\
0 \\
0 \\
10\end{array}$ & $\begin{array}{c}57 \cdot 9 \\
0 \\
0 \\
30 \cdot 6 \\
3 \cdot 3 \\
0 \\
0 \\
8 \cdot 3\end{array}$ & \multirow[t]{2}{*}{80} & \multirow[t]{2}{*}{$66 \cdot 1$} & \multirow[t]{2}{*}{80} & \multirow[t]{2}{*}{$66 \cdot 1$} & \multirow[t]{2}{*}{117} & \multirow[t]{2}{*}{$96 \cdot 7$} \\
\hline & \multicolumn{5}{|c|}{$70(57 \cdot 9) 107(88 \cdot 4) 111(91 \cdot 7)$} & & & & & & \\
\hline \multicolumn{12}{|c|}{$\begin{array}{l}\text { * Four cases of }+/- \text { reaction reported as a negative result } \\
+ \text { One case of meningovascular and three cases of asymptomatic neurosyphilis } \\
+ \text { Positive - negative }\end{array}$} \\
\hline \multicolumn{12}{|c|}{$\begin{array}{l}\text { Table } 5 \text { Results of the } \\
\text { cases of latent syphilis }\end{array}$} \\
\hline & & & & \multirow{2}{*}{\multicolumn{2}{|c|}{$\begin{array}{l}\text { Total no. } \\
\text { of samples }\end{array}$}} & \multicolumn{6}{|c|}{ Agreement between tests } \\
\hline & \multicolumn{3}{|c|}{ Test results } & & & \multicolumn{2}{|c|}{$V D R L: M H A$} & \multicolumn{2}{|c|}{$V D R L: F T A$} & \multicolumn{2}{|c|}{$M H A: F T A$} \\
\hline & $V D R L$ & $M H A$ & $F T A$ & No. & $\%$ & No. & $\%$ & No. & $\%$ & No. & $\%$ \\
\hline \multirow[b]{2}{*}{$\begin{array}{l}\text { Total no. } \\
\text { reactive }(\%)\end{array}$} & $\begin{array}{l}+ \\
+ \\
+ \\
- \\
- \\
+ \\
-\end{array}$ & $\begin{array}{l}+ \\
+ \\
+ \\
+ \\
+ \\
+\end{array}$ & $\begin{array}{l}+ \\
\pm \\
+ \\
+ \\
+ \\
+\end{array}$ & $\begin{array}{r}11 \\
0 \\
0 \\
42 \\
1 \\
0 \\
0 \\
62\end{array}$ & $\begin{array}{c}9 \cdot 5 \\
0 \\
0 \\
36 \cdot 2 \\
0 \cdot 9 \\
0 \\
0 \\
53 \cdot 4\end{array}$ & 74 & $63 \cdot 8$ & 73 & $62 \cdot 9$ & \multirow[t]{2}{*}{115} & \multirow[t]{2}{*}{$99 \cdot 1$} \\
\hline & $11(9 \cdot 5)$ & $53(45$. & $54(46$ & & & & & & & & \\
\hline
\end{tabular}

+ Positive - negative

VDRL-CSF and MHA:TP-CSF tests remained more or less the same as in the previous cases, the agreement between the MHA:TP-CSF and FTA-CSF tests rose to $99 \cdot 1 \%$.

\section{Congenital syphilis}

Of the eight CSF samples from patients with congenital syphilis only one gave a reactive result in all three tests.

\section{Diseases other than syphilis}

No reactivity with any of the three tests was found in CSF samples from 499 patients with diseases other than syphilis (Table 6).

\section{Discussion}

Most authors consider that the TPHA technique is as specific and sensitive as the FTA-ABS test in detecting treponemal serum antibodies in syphilis, except in cases of primary syphilis (Tomizawa et al., 1969; Garner et al., 1973; Kiraly and Prerau, 1974) and that the antibody appears later than the one detected by the FTA-ABS test and probably also by the VDRL test (Rudolph, 1976). On the contrary, Jephcott et al. (1977) reported a case in which the TPHA test was the first to give a positive result in serum compared with the VDRL and FTA-ABS tests. Similarly, Monsiorska-Borowska (1977) found the TPHA test to be more sensitive than the FTA, TPI, and VDRL tests.

It is known that the central nervous system is affected early in the course of early syphilis (O'Neill et al., 1973; Lejman et al., 1976; Kopecky, 1977), but efficient serological tests are not available for detecting treponemal antibodies in CSF in the early stages of syphilis. Previous work done in this laboratory has shown that the FTA-CSF test is capable of detecting treponemal antibodies in $65.9 \%$ of cases of secondary syphilis (Leclerc et al., 1978) and this is confirmed by the present study. 
Table 6 Results of the VDRL-CSF, MHA:TP-CSF, and FTA-CSF tests performed on CSF samples from 499 patients with diseases other than syphilis

\begin{tabular}{|c|c|c|c|c|c|c|c|c|c|}
\hline \multirow[b]{2}{*}{ Diseases } & \multicolumn{3}{|c|}{ Test results } & \multirow{2}{*}{$\begin{array}{l}\text { Total no. } \\
\text { of samples }\end{array}$} & \multirow[b]{2}{*}{ Diseases } & \multicolumn{3}{|c|}{ Test results } & \multirow{2}{*}{$\begin{array}{l}\text { Total no. } \\
\text { of samples }\end{array}$} \\
\hline & $V D R L$ & TPHA & $F T A$ & & & $V D R L$ & TPHA & FTA & \\
\hline Anaemia & - & - & - & 4 & Labyrinthitis & - & - & - & 3 \\
\hline Aphasia & - & - & - & 4 & Lumbar adherence & - & - & - & 8 \\
\hline Ataxia & - & - & - & 12 & Lupus erythymatosus & - & - & - & 4 \\
\hline Cardiac insufficiency & - & - & - & 7 & Medullary compression & - & - & - & 4 \\
\hline Cerebral atrophy & - & - & - & 6 & Meningitis & - & - & - & 43 \\
\hline Cerebral metastases & - & - & - & 1 & Migraine & - & - & - & 10 \\
\hline Cerebral syndrome & - & - & - & 11 & Multiple myeloma & - & - & - & 2 \\
\hline Cerebral thrombosis & - & - & - & 11 & Multiple sclerosis & - & - & - & 35 \\
\hline Cerebral tumour & - & - & - & 4 & Myelitis & - & - & - & 13 \\
\hline Dementia & - & - & - & 16 & Neuritis & - & - & - & 12 \\
\hline Diabetes & - & - & - & 7 & Paralysis & - & - & - & 17 \\
\hline Discal hernia & - & - & - & 60 & Paraplegia & - & - & - & 5 \\
\hline Encephalomyeloneuropathy & - & - & - & 23 & Parkinson's diseases & - & - & - & 5 \\
\hline Epilepsy & - & - & - & 55 & Pick's disease & - & - & - & 1 \\
\hline Fever & - & - & - & 5 & Pneumonia & - & - & - & 9 \\
\hline Genital herpes & - & - & - & 5 & Polyarthritis & - & - & - & 3 \\
\hline Hemiplegia & - & - & - & 6 & Polyneuropathy & - & - & - & 5 \\
\hline Hepatitis & - & - & - & 1 & Portal systemic & & & & \\
\hline Hydrocephaly & - & - & - & 17 & encephalopathy & - & - & - & 8 \\
\hline Hypertension & - & - & - & 6 & Reticulopathy & - & - & - & 1 \\
\hline Hyperthermia & - & - & - & 6 & Seizures & - & - & - & 19 \\
\hline Hypophyseal tumour & - & - & - & 3 & Toxoplasmosis & - & - & - & 4 \\
\hline Hypophyseal disease & - & - & - & 5 & Tuberculosis & - & - & - & 6 \\
\hline \multirow[t]{2}{*}{ Infectious diseases } & - & - & - & 3 & Vasculitis & - & - & - & 3 \\
\hline & & & & & Viraemia & - & - & - & 1 \\
\hline
\end{tabular}

- Negative

The evaluation of the MHA:TP-CSF test-a simpler and less costly technique than the FTA-CSF test-with 2940 non-syphilitic cases indicates that a false-positive result in this test is very rare and that the test is highly specific for treponemal antibodies. Our data supports the observations of Jaffe et al. (1978) regarding the high specificity of the TPHA. It further indicates that this test is sensitive in detecting treponemal antibodies in the early stages of syphilis. It was still not possible to detect antibodies in CSF samples from any of the patients with primary syphilis by the two treponemal tests. At later stages of syphilis the test compares well with the FTA-CSF test, thus supporting the observation of MonsiorskaBorowska (1977). Jaffe et al. (1978) did not find any reactivity in patients with latent syphilis, probably because of the small number of cases studied.

The MHA:TP-CSF test results were stable and reproducible even after repetition at long intervals of time, provided that the specimen was stored frozen.

Specificity in the FTA-CSF test increases if the test is performed on CSF samples diluted to $1 / 5$ in sorbent but, in some cases, it may lose sensitivity and give false-negative results. CSF samples from 16 known cases of syphilis, of which 11 were from cases of secondary syphilis, four from cases of tertiary syphilis, and one from a case of late latent syphilis, giving non-reactive results in the VDRL-CSF and MHA:TP-CSF tests and reactive results in the FTACSF test, became non-reactive in the latter test when the CSF was retested after absorption. This finding confirms the results of Duncan et al. (1972) who found a reduction in the reactivity of the FTA-CSF test after dilution of the CSF in the sorbent. On the other hand, of the same 16 CSF samples when retested undiluted by the MHA:TP-CSF method, 13 (nine from cases of secondary, three of tertiary, and one of latent syphilis) became reactive, thus indicating that the manufacturer's instructions for serum TPHA, where serum is used at a dilution of $1 / 20$, may not apply to the detection of treponemal antibodies in CSF. Diluting the CSF reduces the concentration of immunoglobulins shown by both the low reactivity in the FTA-CSF test and nonreactivity in the MHA:TP-CSF test. Further studies of the MHA:TP-CSF test using undiluted CSF are in progress.

The reactivity in CSF samples from cases of latent syphilis in all the three tests indicates that those cases were syphilitic and not biological false-positive reactors. In the absence of other features they would have been diagnosed as latent cases without the CSF examination. Some may have been previously treated.

Data indicate that the MHA:TP-CSF test is almost identical in specificity but inferior in sensitivity to the FTA-CSF test. The former test, being simple and more economical to perform, can be easily automated for the routine detection of treponemal antibodies in large numbers of CSF samples. 
The authors acknowledge the valuable help of Gérard Larose for frequent discussions and of Danielle Wilson for criticisms and presentation of the manuscript and secretarial assistance.

\section{References}

Bowszyc, J. (1975). The cerebrospinal fluid in syphilis in the aspect of immunological studies. Przeglad Dermatologiciny, 60 , 365-372.

Coffey, E. M., Bradford, L. L., Naritomi, L. S., and Wood, R. M. (1972). Evaluation of the qualitative and automated microhemagglutination assay for antibodies to Treponema pallidum. Applied Microbiology, 24, 26-30.

Communicable Disease Center (1969). Manual of Tests for Syphilis. Edited by US Department of Health, Education and Welfare. UPHSP Publication No. 411. US Government Printing Office: Washington, DC.

Communicable Disease Center (1973). Microhemagglutination assay for Treponema pallidum antibodies (MHA-TP), Edited by US Department of Health, Education and Welfare. US Government Printing Office: Washington, DC.

Cox, P. M., Logan, L. C., and Stout, G. W. (1971). Further studies of quantitative automated microhemagglutination assay for antibodies to Treponema pallidum. Public Health Laboratories, 29. 43-50.

Duncan, W. P., Jenkins, T. W., and Parham, C. E. (1972). Fluorescent treponemal antibody cerebrospinal fluid (FTA-CSF) test. A provisional technique. British Journal of Venereal Diseases, 48, 97-101.

Garner, M. F., Backhouse, J. L., Daskalopoulos, G., and Walsh, J. L. (1972). Haemagglutination test for syphilis. Comparison with the TPI and FTA-ABS tests. British Journal of Venereal Diseases, 48, 470-473.

Garner, M. F., Backhouse, J. L., Daskalopoulos, G., and Walsh, J. L. (1973). The Treponema pallidum haemagglutination (TPHA) test in biological false-positive and leprosy sera. Journal of Clinical Pathology, 26, 258-260.

Jaffe, H.W., Larsen, S. A., Peters, M., Franco Jove, D., Lopez, B., and Schroeter, A. L. (1978). Test for treponemal antibody in CSF. Archives of Internal Medicine, 138, 252-255.

Jephcott, A. E., Beveridge, M. A. M., and Sequiera, P. J. L. (1977). Early TPHA response in primary syphilis. British Journal of Venereal Diseases, 53, 147.
Kasatiya, S. S., and Birry, A. (1972). The use of incident light in immunofluorescence applied to syphilis serology. American Journal of Clinical Pathology, 57, 395-399.

Kiraly, K., and Prerau, H. (1974). Evaluation of the Treponema pallidum haemagglutination (TPHA) test for syphilis on 'problem sera'. Acta dermato-venereologica (Stockholm), 54, 303-310.

Kopecky, K., Uhlikova, M., and Fadrhoncova, A. (1977). A microhaemagglutination test in the diagnosis of syphilis. Journal of Hygiene, Epidemiology, Microbiology, and Immunology, 21, 23-32.

I.eclerc, G.. Giroux, M., Birry, A., and Kasatiya, S. (1978). Study of fluorescent treponemal antibody test on cerebrospinal fluid using monospecific anti-immunoglobulin conjugates $\mathrm{IgG}, \mathrm{IgM}$ and IgA. British Journal of Venereal Diseases, 54, 303-308.

Lejman, K., Starzycki, A., Mieszynska-Wöjeik, L., Szwarc, J., and Mayer, K. (1976). Changes in the various systems' in the course of carly syphilis. Przeglad Dermatologiczny, 63, 387-394.

Lesinski, J., Krach, J., and Kadziewicz, E. (1974). Specificity, sensitivity and diagnostic value of the TPHA test. British Journal of Venereal Diseases, 50, 334-340.

Luger, A., and Spendlingwimmer, I. (1973). Appraisal of the Treponema pallidum haemagglutination test. British Journal of Venereal Diseases, 49, 181-182.

Monsiorska-Borowska, L.. (1977). TPHA reaction in cerebrospinal fluid in late syphilis. Przeglad Dermatologiczny, 64, 705-710.

O'Neill, P., Warner, R. W., and Nicol, C. S. (1973). Treponema pallidum haemagglutination assay in the routine serodiagnosis of treponemal disease. British Journal of Venereal Diseases, 49. 427-431.

Oxelius, V., Rorsman, H., and Laurell, A. (1969). Immunoglobulins of cerebrospinal fluid in syphilis. British Journal of Venereal Diseases, 45, 121-124.

Rathlev, T. (1967). Haemagglutination test utilising pathogenic Treponema pallidum for the serodiagnosis of syphilis. British Journal of Venereal Diseases, 43, 181-185.

Rudolph, A. H. (1976). The microhemagglutination assay for Treponema pallidum antibodies (MHA-TP), a new treponemal test for syphilis: where does it fit? Journal of the American Venereal Diseases Association, 3, 3-8.

Sequeira, P. J. L., and Eldridge, A. E. (1973). Treponemal haemagglutination test. British Journal of Venereal Diseases, 49. 242-248.

Tomizawa, T., Kasamatsu, S, and Yamaya, S. (1969). Usefulnes of the hemagglutination test using Treponema pallidum antigen (TPHA) for the serodiagnosis of syphilis. Japanese Journal of Medical Science and Biology, 22, 341-350.

Young, M., Henrichsen, C., and Robertson, D. H. H. (1974). Treponemal pallidum haemagglutination test as a screening procedure for the diagnosis of syphilis. British Journal of Venereal Diseases, 50, 341-346. 